\title{
Spatio-Temporal Assessment of "Chlorophyll a" in Banco Chinchorro Using Remote Sensing
}

\author{
Hugo E. Lazcano-Hernandez ${ }^{1}$, Javier Arellano-Verdejo ${ }^{2}$, \\ Hector A. Hernandez-Arana ${ }^{2}$, M. Susana Alvarado-Barrientos ${ }^{3}$ \\ ${ }^{1}$ CONACYT-ECOSUR Chetumal, Laboratorio de estructura y función del bentos, \\ ERIS, Mexico \\ 2 ECOSUR Chetumal, Laboratorio de estructura y función del bentos, ERIS, \\ Chetumal, Quintana Roo, Mexico \\ 3 Instituto de Ecologa A.C., Red de Ecologa Funcional, Xalapa, Veracruz, Mexico \\ hlazcanoh@ecosur.mx
}

\begin{abstract}
Quantitative assessments of the temporal variances of physical and biological phenomena are very useful for the understanding of ecosystem functioning. Marine ecosystems are very complex, and regarding biodiversity and fishing resources, Banco Chinchorro (BCh) is one of the most important in the south of the Yucatan Peninsula. Additionally, $\mathrm{BCh}$ is an important hotspot of assimilation and release of carbon, for which hurricanes play a supporting role by mixing deep and superficial water masses affecting nutrient mixing and distribution. Here, the concentration of chlorophyll a ( $C h l a)$ was quantitatively linked to the occurrence of the four most recent hurricanes that affected $\mathrm{BCh}$ utilizing time-series analysis of satellite-derived (AQUA-MODIS) datasets. Interestingly, different $C h l a$ concentrations between the south and north of BCh were confirmed quantitatively, which points to differential conservation efforts. The aim of this study was also to provide a proof-ofconcept for the development of long-term monitoring methodology using remotely sensed data so that it may be replicated in other regions and with other satellite databases.
\end{abstract}

Palabras clave: remote sensing, time series analysis, AQUA MODIS, chlorophyll $a$, Banco Chinchorro, Hurricanes.

\section{Introduction}

In-situ observation and data collection from coastal and marine ecosystems in tropical areas remain a challenging endeavor. Coastal and marine tropical systems are complex in nature and subjected to several environmental forcing that drives its structure and function. This complexity is particularly evident in the Mexican Caribbean, a coastal and marine region with a wide ecosystem diversity that ranges from flooded forests, flood plains, wetlands, mangroves, freshwater lakes, coastal lagoons, coral reef lagoons, coral reef ecosystems and an oceanic realm $[1]$. 
To generate scientific knowledge and operational remote-sensing products a collaborative framework is required such that specialists in different areas of knowledge contribute. Spatio-temporal analysis of $C h l a$ on $\mathrm{BCh}$ requires computational analysis of satellite datasets that can later be interpreted by a specialist in marine biology.

BCh has been studied by marine biological sciences for many years, however, the satellite remote sensing analysis has not been applied in depth in the region yet. The aim of this research is to create a Chl $a$ foundation knowledge, to create a Chl $a$ index to the region as [2]

The main aspects of different knowledge areas that were required for the analysis of $C h l a$ in BCh are discussed in the present paper. In subsection 1.1 the stages that constitute the remote sensing processes are listed. Subsection 1.2 presents a brief summary of the satellite platforms and some technical aspects of AQUA. In subsection 1.3 some technical aspects of AQUA-MODIS sensor are presented. In subsection 1.4 some technical aspects of AQUA-MODIS datasets are explained. Subsection 1.5 shows the importance of hydro-meteorological phenomena for marine ecosystems. Later in Section 2, the ecological and economical importance of $\mathrm{BCh}$ for the region is summarized, as well as the relationship between hydro-meteorological phenomena and BCh. Subsequently in Section 3, the computer procedures and mathematical techniques that were applied in $C h l$ $a$ dataset are explained. Finally in Section 4, the contribution of this research is given.

\subsection{Remote Sensing}

Currently, satellite remote sensing is one of the main sources of quantitative spatial and temporal data, used to expand all aspects of Earth Sciences. The remote sensing process includes several very important subprocesses such as: satellite platform observation, data reception at a ground station, raw data preprocessing, data corrections, high level data analysis and final interpretation of the data by the end user. A schematic of remote sensing process is shown in Figure 1. The work done for this paper corresponds to the high level data analysis and final interpretation stages.

\subsection{AQUA Platform}

Currently, very different types of space missions (i.e. civil, commercial, communications, Earth observation) operate around the world. In the area of civil Earth observation, the AQUA mission is highlighted given the prolonged time that it has remained in operation and for the number of products that it offers. AQUA, or EOS-PM, was launched in May 2002. Its orbit is helio-synchronous and quasi-polar with an inclination of $98^{\circ}$ and an average altitude of $705 \mathrm{~km}$ [3]. AQUA passes from south to north over the equator at 1:30 pm, which allows observation scenes of the Caribbean Sea with the sun very close to the zenith. 

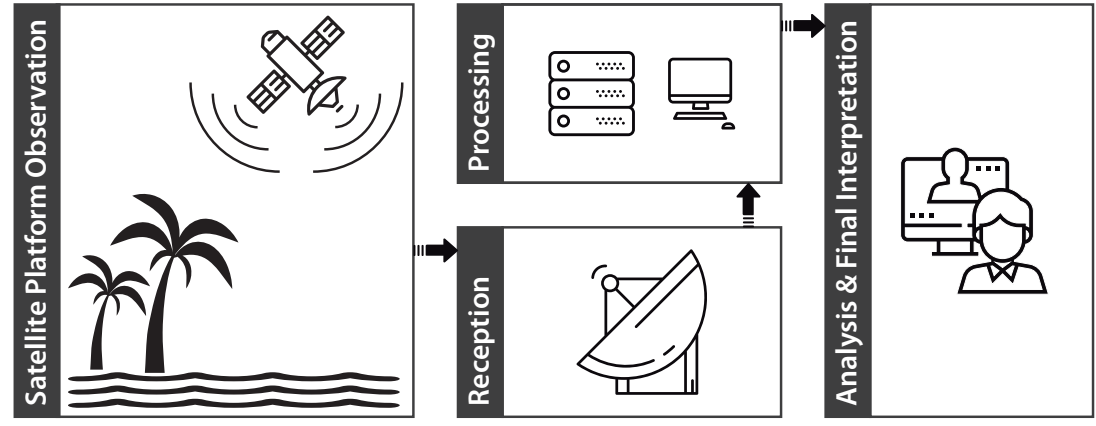

Fig. 1. Remote sensing

\subsection{MODIS Sensor}

One of the instruments that travels on board AQUA is the MODIS sensor. It is remarkable that all MODIS sensor products are freely available for download, through various NASA portals [4]. The MODIS instrument has 12-bit radiometric sensitivity and 36 spectral bands with a wavelength ranging from $0.4 \mu \mathrm{m}$ to $14.4 \mu \mathrm{m}[3]$. It has a high geometric quality that allows the precise monitoring of the alterations of the terrestrial surface (RMS error of less than $50 \mathrm{~m}$ ). The MODIS sensor is a sweeping scanner, that is, a mobile mirror that oscillates perpendicularly to the direction of the trajectory with an angle of $\pm 55^{\circ}$ allowing the exploration of a strip of land on both sides of the satellite trace, whose width is $2,330 \mathrm{~km}$. The optical system is a telescope with two mirrors outside its focal axis that direct the incident radiation to four reflective optical systems, one for each spectral region (visible, near infrared, medium and thermal). A silicon photodiode technology is used for the visible and near-infrared bands and mercury-Cadmium Teluret $(\mathrm{HgCdTe})$ detectors are used for the thermal infrared[3].

\subsection{Chlorophyll a Datasets}

MODIS products are divided into five levels ( 0 to 4 ) depending on the processing level [3]. For the present study, level 3 Chlorophyll $a$ concentration ( $C h l a)$ from AQUA-MODIS satellite platform, were used [5]. Chl $a$ data gives near-surface concentration of $C h l a$ in $\left[\mathrm{mg} / \mathrm{m}^{3}\right]$, calculated using an empirical relationship derived from in situ measurements of Chl $a$ and blue-to-green band ratios of in situ remote sensing reflectances (Rrs) [4]. Bands $9(443 \mathrm{~nm}), 10(488 \mathrm{~nm})$ and 12 $(551 \mathrm{~nm})$ were used to calculate $C h l a[6]$. Each data has a pixel size of $4.6 \mathrm{~km}$ per side, therefore 108 pixels were needed to complete one scene of $\mathrm{BCh}$. The available information from AQUA starts in July 2002 and ends on April 2018, thus 190 matrices were analyzed.

Chl a datasets are the result of a remote sensing processing algorithm used to calculate the amount of phytoplankton biomass in the sea [5], because as 
green plants, phytoplankton contains chlorophyll, which is the most abundant photosensitive molecule in nature and through which photosynthesis is possible. Phytoplankton photosynthesis is fundamental for various biogeochemical processes in the oceans and thus, constitutes the foundation of life in the oceans [7]. One of the potential benefits of using satellite information to derive chlorophyll concentration is that it allows continuous monitoring of phytoplankton.

\subsection{Hurricanes}

Tropical storms and hurricanes are a recurrent hydro-meteorological phenomena in the Caribbean basin and constitute the major physical disturbance for coastal areas [8]. Tropical storms and hurricane effects have been evaluated for both natural and human systems highlighting their negative impact on coral reefs, mangroves, wetlands, forest and on human lives and infrastructure. However, tropical storms and hurricane also possess a positive feedback on natural systems by causing the mixing of deep and superficial water masses with cascading effects in nutrient mixing and distribution. It has been observed that several weeks after a passing storm, the concentration of $C h l a$ is increased and, as a consequence, carbon fixation and phytoplankton biomass increase [9]. Therefore, life is activated. In order to assess whether the same ecosystem-level and short-term response can be observed using available satellite data for a small area such as the BCh reef, the spatio-temporal distribution of Chl a was compared with the occurrence of extreme hydro-meteorological events that directly affected BCh, during the study period: Dean, Karl, Ernesto and Earl hurricanes (Table 1).

Table 1. Hurricanes with impact on Banco Chinchorro.

\begin{tabular}{|c|c|c|c|c|c|}
\hline Name & $\begin{array}{c}\text { Date over } \\
\text { BCh }\end{array}$ & $\begin{array}{l}\text { Maximum } \\
\text { cathegory }\end{array}$ & $\begin{array}{l}\text { Cathegory } \\
\text { over BCh }\end{array}$ & $\begin{array}{c}\text { Displacemen } \\
\text { Vel } \mathrm{km} / \mathrm{h}\end{array}$ & $\begin{array}{l}\text { Maximum winds } \\
\text { over BCh } \mathrm{km} / \mathrm{h}\end{array}$ \\
\hline Dean & 19 Ago 2007 & H5 & $\mathrm{H} 5$ & 32 & 232 \\
\hline Karl & 15 Sep 2010 & H3 & $\mathrm{TT}$ & 13 & 90 \\
\hline Ernesto & 08 Ago 2012 & $\mathrm{H} 2$ & TT-H1 & 24 & 116 \\
\hline Earl & 04 Ago 2016 & $\mathrm{H} 1$ & H1-TT & 22 & 119 \\
\hline
\end{tabular}

\section{Study Area}

The Banco Chinchorro reef (BCh; Figure 2) was selected for this analysis, due to its great ecological and economic importance for the south of the Mexican Caribbean. BCh is a coral reef of irregular oval form, with a length of $43 \mathrm{~km}$ in its longest part, and $18 \mathrm{~km}$ in its widest part. It is located southeast of the Yucatan Peninsula ( $\left.18^{\circ} 36^{\prime} 15^{\prime \prime} \mathrm{N}, 87^{\circ} 21^{\prime} 15^{\prime \prime} \mathrm{W}\right)$, at $30.8 \mathrm{~km}$ of the coast, separated by a channel with a maximum depth of $1000 \mathrm{~m}$. In the windward there is a very well developed reef, which confers a gentle slope, whereas in the 
leeward, the slopes are abrupt reaching down to $500 \mathrm{~m}$ of depth $[10,13]$. The depth of the study area ranges from 7 to $9 \mathrm{~m}$ in the southern portion and $2 \mathrm{~m}$ in the north, where marine grasses abound such as Thalassia testudinum [13]. The cays are surrounded by a mangrove ecosystem dominated red mangrove (Rhizophora mangle) and black mangrove (Avicennia germinans). The area is influenced by natural disturbances such as storms and hurricanes that damage mangrove vegetation. During the study period the eastern coast of the Yucatan Peninsula has been affected by two tropical storms and 12 hurricanes with direct impact to BCh in 2007 by Dean, in 2010 by Karl, in 2012 by Ernesto and in 2016 by Earl (Table 1). The area is also vulnerable to global climate change effects such as rising mean sea level and ocean acidification. Also, bleaching due to increased sea temperature threat to reduce coral cover [10]. Other local threats to the $\mathrm{BCh}$ ecosystems include overfishing. For instance, the commercially important threatened species pink snail (Strombus gigas) maintained abundant densities in the reserve but have began to decline since 1990 [13]. Likewise, the spiny lobster (Panulirus argus) is under a temporary fishing ban [14].

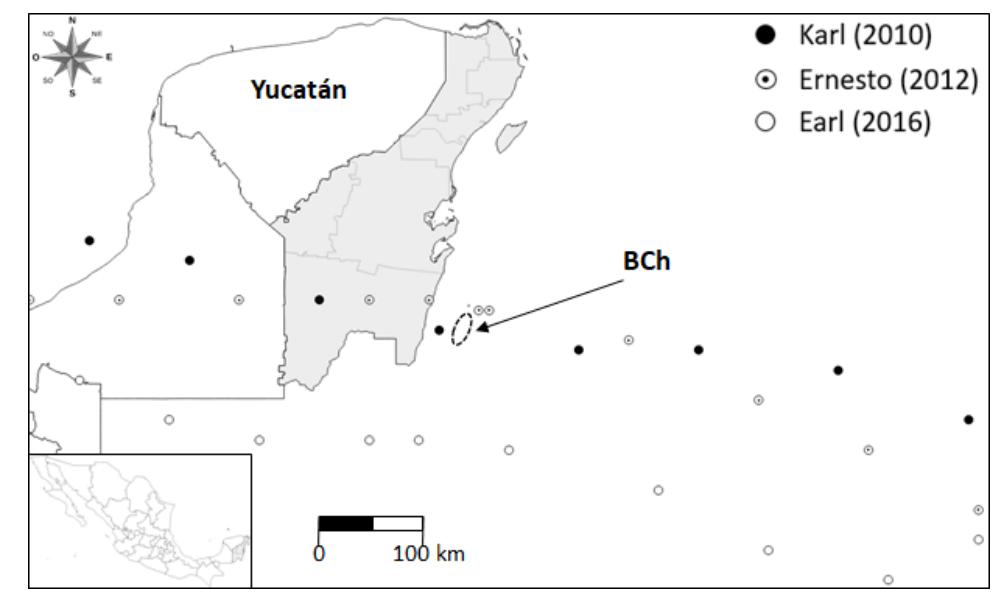

Fig. 2. Location map of Banco Chinchorro (BCh) and paths of hurricanes Karl, Ernesto and Earl.

Therefore, it is relevant to develop and evaluate methods to remotely monitor and study the dynamics of $C h l$ a concentration at BCh because the food chain starts with phytoplankton and any event that quickly changes its concentration can trigger a cascade of ecosystem-level responses. As such, spatio-temporal knowledge of $C h l$ a concentration is critical for the development of environmental preservation and fishing management proposals based on quantitative data and scientific information. 


\section{Data Analysis}

Monthly Chl a datasets from AQUA-MODIS [4], were used and cropped out only to analyze the $\mathrm{BCh}$ area. Resulting bitmap files used were 9 pixels wide by 12 long (Figure 3). In total, 190 bitmap files were used in this study (from July 2002 to April 2018).

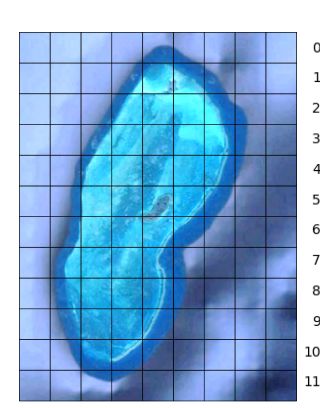

a) BCh Satellite view

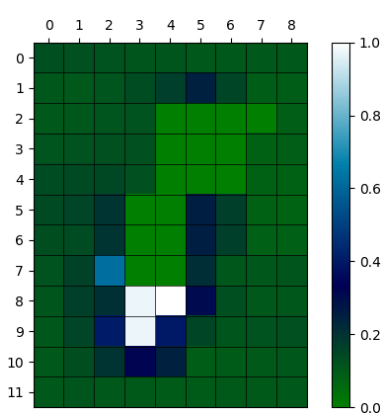

b) Concentration map of $C h l a$ in $\mathrm{BCh}$

Fig. 3. Banco Chinchorro coral reef.

A time-series (Fig. 4) and spatial analysis per pixel of each file were applied (Fig. 8). For a more precise analysis, the time series were divided into its components: trend $(T)$, seasonal $(S)$ and remainder component $(R)$ [15]. Equation 1, shows the components of a dataset $(Y)$, for $v=1$ to $N$.

$$
Y_{v}=T_{v}+S_{v}+R_{v}
$$

In this way, it was possible to analyze only the trend information, which in our case, is the most valuable, as the periodicity is already known and the noise contains no desirable information (Fig. 5).

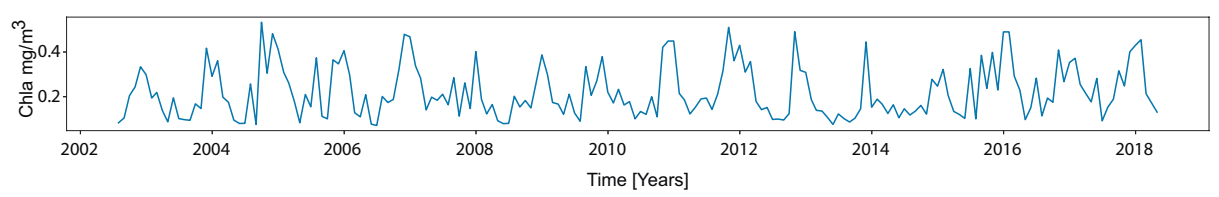

Fig. 4. Time series of the mean concentration of $c h l a$ in Banco Chinchorro.

To know Chl a levels in BCh before, during and after a hurricane, the four most recent hurricanes that affected BCh were located over the time series. Every hurricane has very specific features, which were considered in the analysis. Such features at the moment of hitting BCh are shown in Table1. 


\section{Results}

The Chl a time-series was analyzed by a twelve-months mobile mean. Focused only on the trend information, only two of the four hurricanes were related with the lowest concentration values of $C h l a$ (Figure 5b). It was expected that the occurrence of all events would be related to the minimum $C h l$ a values, but that was not observed with a twelve-months mobile mean periodicity. From the computational point of view, it was not clear how to find the adequate periodicity to an accurate analysis. However, from the point of view of nature, it is obvious. It is known that hurricanes in the northern hemisphere (Atlantic Ocean) only occur during the months of May to November. Therefore, the mobile mean of the analysis was adjusted at six months. Fig. 6 clearly shows that hurricanes Earl and Ernesto also occurred at the lowest levels of $C h l a$, while this was not evident from the annual periodicity analysis.

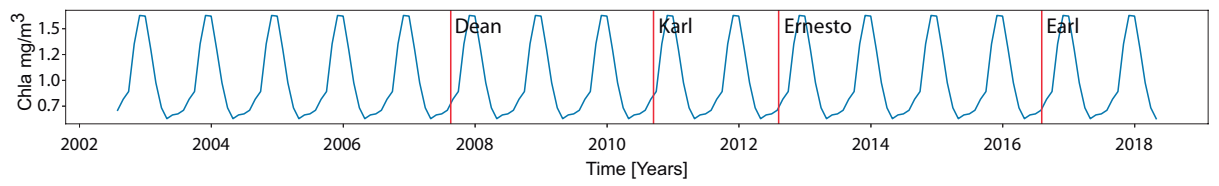

a) Seasonal

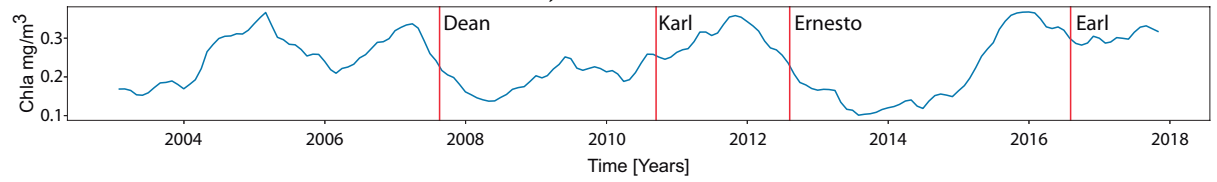

b) Trend with twelve-month moving average

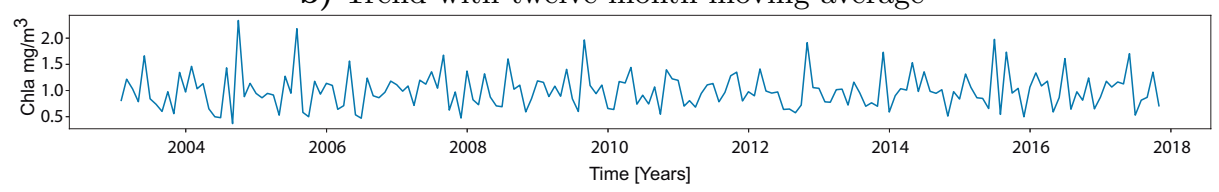

b) Noise

Fig. 5. Decomposition of the chlorophyll concentration time series.

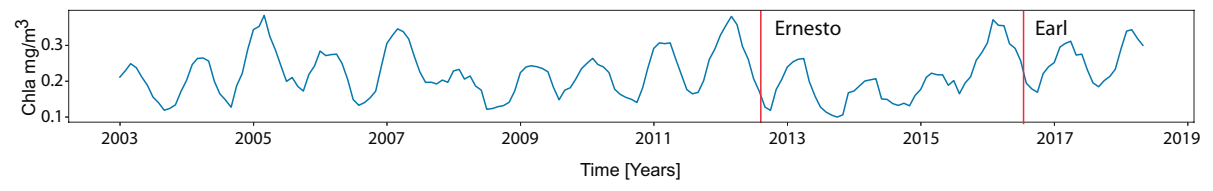

Fig. 6. Trend with 6-month moving average. 
Because of the large amount of water and clouds over the sea during the occurrence of hurricanes, the MODIS optical sensor is practically blind. Thus, the sensor is unable to observe the sea surface, therefore it cannot produce any Chl a measurement. As an example, satellite images of Ernesto and Earl are shown in Figure $7 \mathbf{a}$ and $7 \mathbf{d}$, respectively.

AQUA-MODIS sensor can observe the sea surface again some days after the hurricane passes due to such factors as: clouds and sensor technical issues. On the other hand, the increments of $C h l a$, it is observable and measured until the second month after a hurricane passes due to biological processes. As an example, see Figures: $7 \mathbf{b}$ and $7 \mathbf{c}$ which exemplify Ernesto, and Figures $7 \mathbf{e}$ and 7f which exemplify Earl.

Another important aspect seen in Figures $7 \mathbf{b}$ and $7 \mathbf{e}$, is that concentrations of chl $a$, are higher in the southern of BCh compared to the north. Ergo, before the subsidy of nutrients and energy driven by the hurricane is used, in the southern zone of $\mathrm{BCh}$, a very high concentration of chl $a$ is observed.

Figure 8 strengthens the aforementioned. Regarding Ernesto, Figure 8a shows that Chl $a$ in the southern zone of BCh is higher compared to the north. After that, from the next month, the increase of $C h l a$ in whole BCh is shown in Figure $8 \mathbf{b}$. This suggests that southern $\mathrm{BCh}$ is a bastion for the entire reef. Therefore, from the point of view of this analysis, southern zone of $\mathrm{BCh}$, is placed as a strategic region for the preservation of the whole reef.

Regarding Earl, the same situation described for Ernesto was observed, (figures $8 \mathbf{c}$ and $8 \mathbf{d}$ ). Therefore, the conclusion that, the southern zone is a bastion for the reef is confirmed. On the other hand, it is acknowledged that four events are probably not a large enough sample. However, the hurricanes that have affected BCh from 2002 to 2018 (the time period of AQUA-MODIS operation), have only been four.

\section{Future Work}

Analysis with SATMO [6] datasets is the natural next step in this research, because SATMO offers a spatial resolution of one kilometer per pixel. Additionally applied Chl $a$ algorithms in optical bands of other satellite missions as "Sentinel 2 " or landsat is missing. Finally in situ measurements of Chl a are still missing to calibrate satellite dataset.

\section{Conclusions}

Through a time-series and spatial analysis AQUA-MODIS datasets, the concentration of chlorophyll $a$ was quantitatively linked to the four most recent hurricanes that affected $\mathrm{BCh}$. Additionally, very important Chl a concentration differences between the south and north of $\mathrm{BCh}$ were confirmed. Compared to the north of BCh, the southern zone always maintains chlorophyll a concentrations an order of magnitude higher. 


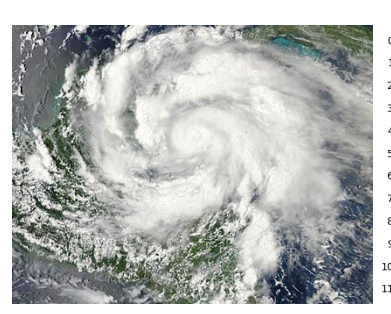

a) Hurricane Ernesto

$\mathrm{h}$

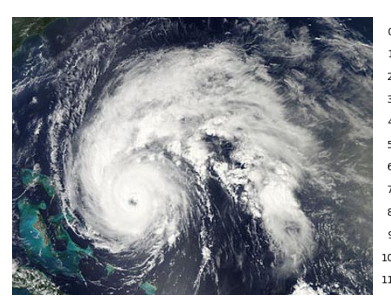

d) Hurricane Earl

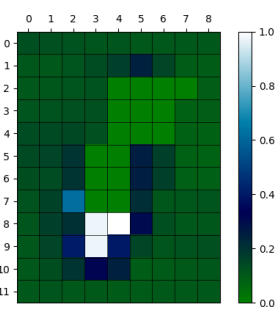

b) After Ernesto Sept. 2012

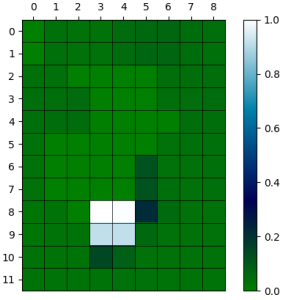

e) After Earl Sept. 2016

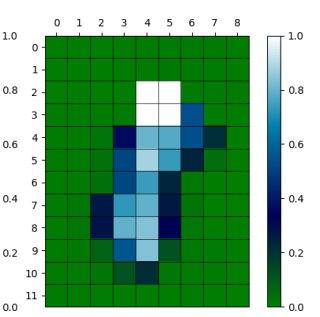

c) After Ernesto Oct. 2012

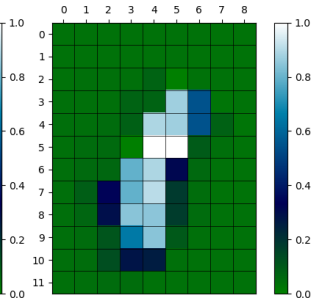

f) After Earl Oct. 2016

Fig. 7. Hurricanes and BCh raster images of $C h l a\left[m g / \mathrm{m}^{3}\right]$.

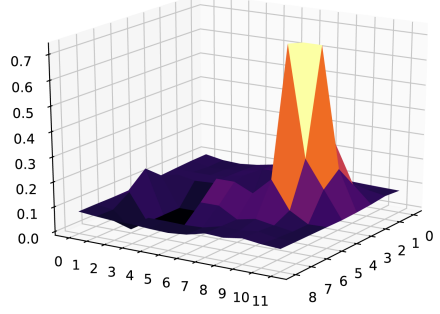

a) After Ernesto Sept. 2012

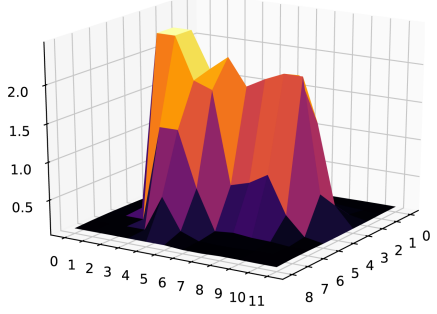

b) After Ernesto Oct. 2012

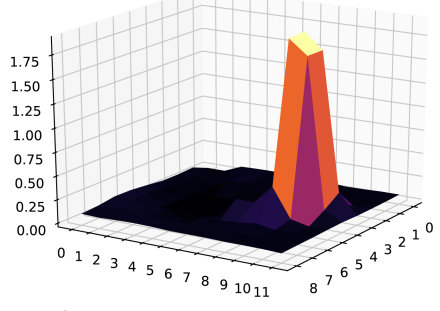

c) After Earl Sept. 2016

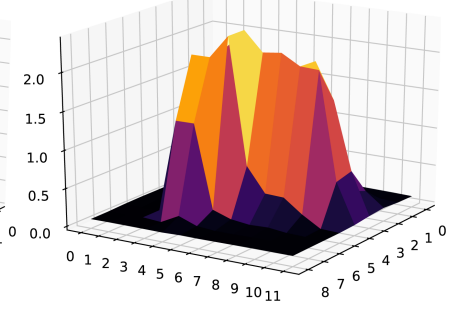

d) After Earl Oct. 2016

Fig. 8. Spatial Chl a concentration on BCh. Axis: $z\left[\mathrm{mg} / \mathrm{m}^{3}\right] ; x, y$ length $[$ pixel $]$. 
This study presents remotely sensed evidence of the influence of hydrometeorological events such as hurricanes on the generation of important phytoplankton blooms which are involved in the production of critical resources for the food chain, in particular for the sustainability of fisheries. The present study also hints at methodology development towards long-term monitoring of chlorophyll a temporal and spatial trends and studies to quantify the frequency and intensity of hurricanes' impact on coral reefs as well as related effects of climate change. Download, pre-processing, and spatio-temporal analysis of satellite-derived $C h l$ a datasets was possible due to the computation work.

Acknowledgments. The authors acknowledge the Mexican National Council of Science and Technology (CONACYT) for funding through a Catedras project for young scientists (2015-526), to the satellite ground station ERIS for the access to the MODIS historical data collection and to El Colegio de la Frontera Sur (ECOSUR) campus Chetumal for additional support.

\section{References}

1. Hernandez-Arana, H.-A., Vega-Zepeda, A., Ruiz-Zarate, M.-A. Falcon-Alvarez, L.I., Lopez-Adame, H., Herrera-Silveira, J., Kaster, J. Transverse coastal corridor: from freshwater lakes to coral reefs ecosystems. In: Biodiversity and Conservation of the Yucatan Peninsula. Editors. Eslebe G., Calm S., Len-Cortes J. L., Schmook B. Springer Switzerland (2015) https://doi.org/10.1007/978-3-319-06529-8

2. Lacava T., Ciancia E., Di Polito C., Madonia A., Pascucci S., Pergola N, Piermattei V, Satriano V., Tramutoli V.:Evaluation of MODISAqua Chlorophyll-a Algorithms in the Basilicata Ionian CoastalWaters. Remote Sens. 2018, 10, 987, doi:10.3390/rs10070987

3. Jean-Franois M. (coordinator): Aplicaciones del sensor MODIS para el monitoreo del territorio. 2nd edn. SEMARNAT, Mexico (2011)

4. NASA Goddard Space Flight Center, Ocean Ecology Laboratory, Ocean Biology Processing Group: MODIS-Aqua Ocean Color Data; NASA Goddard Space Flight Center, Ocean Ecology Laboratory, Ocean Biology Processing Group (2014)

5. Hu Ch., Lee Z.,Franz B.: Chlorophyll a algorithms for oligotrophic oceans: A novel approach based on three-band reflectance difference. JOURNAL OF GEOPHYSICAL RESEARCH,doi:10.1029/2011JC007395, 117(5), 1-25 (2012)

6. Cerdeira-Estrada S., Lopez-Saldaa G.,A novel satellite-based Ocean Monitoring System for Mexico. Ciencias Marinas 37(2), 237-247 (2011)

7. Allen, J.F.: How does protein phosphorylation regulate photosynthesis?, Trends Biochem. Sci. 1(1), 12-17 (1992)

8. Farfan, L., DSa, E., Liu, K., Rivera-Monroy, V.: Tropical Cyclone Impacts on Coastal Regions: the Case of the Yucatn and the Baja California Peninsulas, Mexico. Estuaries and Coasts, 37, 1388-1402 (2014)

9. Hernandez de la Torre B. y Gilberto Gaxiola-Castro G. (Compiladores): Carbono en ecosistemas acuticos de Mxico. SEMARNAT, Cap.19, 279-292 (2016)

10. Vega-Zepeda, A., Hernandez-Arana, H., Carricart-Ganivet J.P.: Spatial Distribution and Health Condition of Acropora (Cnidaria: Scleractinia) Species in Chinchorro Bank, Mexican Caribbean: Implications for Management. Coral Reefs DOI 10.1007/s00338-007-0245-7. 26(3), 671-676 (2007) 
11. Swain T.D, DuBois E., Goldberg S.J., Backman V., Marcelino L.A.: Bleanching response of coral species in the context of assemblage response. Coral Reefs 36(5), 395-400 (2017)

12. Perez-Santos I., Schneider W., Valle-Levinson A., Garces-Vargas J., Soto I., Montoya-Sanchez R., Melo-Gonzalez N., Muller-Karguer F. :Chlorophyll-a patterns and mixing processes in the Yucatan Basin, Caribbean Sea, Ciencias Marinas, http://dx.doi.org/10.7773/cm.v40i1.2320 40(1), 11-31 (2014)

13. Cala, Y.R., De Jesus-Navarrete A., Ocaa F.A., and Oliva-Rivera J. : Densidad, estructura de tallas y actividad reproductiva del caracol rosado Eustrombus gigas (Mesogastropoda: Strombidae) en Banco Chinchorro, Mxico. Biologa Tropical 61(4), 1657-1669 (2013)

14. Rios-Lara G.V., Espinoza-Mendez J.C., Zetina-Moguel C., Aguilar Cardozo C., Ramirez-Estevez A.: La pesqueria de langosta Panulirus argus en el Golfo de Mxico y mar Caribe mexicano In: Instituto Nacional de Pesca 50 Aniversario 1962-2012, Instituto Nacional de Pesca, Mxico (2013)

15. Cleveland, R. B., Cleveland, W. S., McRae, J. E., \& Terpenning, I.: STL: A Seasonal-Trend Decomposition. Journal of Official Statistics, 6(1), 3-73 (1990) 